\title{
КРИТЕРИИ И МЕТОДЫ ОЦЕНКИ МУЗЫКАЛЬНО-ТВОРЧЕСКОГО РАЗВИТИЯ ЛИЧНОСТИ ОБУЧАЮЩЕГОСЯ НА ЭТАПЕ ВЫСШЕГО ОБРАЗОВАНИЯ
}

\author{
Черемисова (Курышева) Ирина Валерьяновна
}

Разработка критериев и методов оченки музыкально-творческого развития личности студента в образовательном процессе вуза имеет особую актуальность в связи с тем, что выпускник вуза должен обладать не только набором профессиональных компетенций, но и высоким уровнем общей культуры, интеллигентностью, креативностью, духовностью. Авторская позиция состоит в том, что использование формирующих потенциалов музыкального искусства в системе высшего отечественного образования отличается фрагментарностью, ситуативностью. Массовое музыкальное образование в юношеском возрасте обрывается, вопреки традициям отечественного образования дореволючионного периода развития России.

В качестве результата непрерывного массового музыкального образования личности обучающегося автор представляет вторичную музыкальную личность будущего специалиста. Теоретический анализ исследований этого направления показал, что ученые в разных областях знания подчеркивают огромные возможности музыкального искусства для формирования ченностных ориентаций молодежи, обретения смысла жизни, смысла профессиональной деятельности, для возможности творческого самовыражения, самопознания, духовного общения. В то же время, диагностика музыкального и творческого развития личности в психолого-педагогической науке остается неразрешенной проблемой, связанной со сложностью и многогранностью этих феноменов. Особенно остро эта проблема стоит для оченки эффективности программ психологического сопровождения творческого развития личности студента вуза. В статье предпринята попытка восполнить дефицит исследований в указанном направлении с позиций авторского эстетико-семиотического подхода. Для того чтобы оценить изменения, произошедшие в личности обучающегося в процессе экспериментальной работы, разработаны критерии, показатели и соответствующие им уровни развития вторичной музыкальной личности.

Ключевые слова: высшее образование, музыкальное образование, творческое развитие, музыкальное искусство, интеллигентность, критерии, уровень музыкальности, диагностика креативности, диагностика музыкальности, музыкальная личность. 


\section{Введение}

В современной ситуации российская психолого-педагогическая наука уделяет много внимания проблемам модернизации высшего образования. Остро встают вопросы, касающиеся ценностных ориентаций молодежи, поиска смысла профессиональной подготовки на этапе высшего образования, развития субъектности обучающихся $[1,12,22]$. При этом большое значение придается формированию компетенций, позволяющих быть успешным в профессиональной деятельности [1, 22]. Имея в виду две составляющие образования - обучение и воспитание, отметим, что основные усилия по модернизации отечественного высшего образования направлены на всестороннее совершенствование обучения. Психологи и педагоги отмечают недостаточное внимание, недооценивание второй составляющей - именно воспитания будущего специалиста с высшим образованием [7, 11]. Это подразумевает не только набор сформированных компетенций будущего специалиста, но и формирование общей культуры, интеллигентности, развитие духовности личности будущего специалиста [1, 3, 5, 6, 8, 10, 11, 12$]$.

На основе теоретического анализа психолого-педагогических исследований, а также философских научных трудов, мы можем заключить, что мощным формирующим потенциалом для социализации и инкультурации личности обладает классическое музыкальное искусство [3, 5, 13, 18]. В нашем исследовании определяется важнейшая роль массового музыкального образования и музыкального самообразования на этапе вузовского обучения для творческого, духовного развития, формирования интеллигентности будущих специалистов. Результатом музыкального образования личности обучающегося нам представляется формирование вторичной музыкальной личности будущего специалиста $[3,4,10]$. Нами разработано и обосновано понятие «вторичной музыкальной личности».

Вторичную музыкальную личность мы определяем как музыкально-творчески активного субъекта, способного к познанию, оцениванию, описанию, преобразованию окружающей действительности и собственной музыкальнотворческой среды, способного использовать музыку как средство общения в процессе музыкальной деятельности. Для того чтобы оценить изменения, произошедшие в личности обучающегося в процессе экспериментальной работы, мы разработали критерии, показатели и соответствующие им уровни развития вторичной музыкальной личности.

Уровень развития свойств и способностей в психологической структуре вторичной музыкальной личности определяет уровень ее музыкально-речевой и музыкально-языковой компетентности [2], уровень развития музыкального сознания [9]. В нашем исследовании структура вторичной музыкальной личности представлена музыкально-когнитивным, мотивационным, эмоциональным, 
коммуникативным, деятельностным, духовно-нравственным компонентами.

\section{Актуальность проблемы}

Анализ психолого-педагогических исследований, направленных на экспериментальное изучение развития музыкальности творческой личности студента вуза, позволил констатировать их немногочисленность $[13,14,15]$. Скорее всего, это обусловлено отсутствием специальной диагностической технологии в психолого-педагогической науке. В основном при изучении музыкально-творческого развития обучающегося экспериментаторы диагностируют отдельные музыкальные способности. Анализу подвергаются, прежде всего, результаты тестовых испытаний, которые дают представление о количественном выражении музыкальных способностей (если можно так выразиться). В то же время эти методы не позволяют представить оценку качественного своеобразия музыкальных способностей каждого испытуемого, в целом его музыкальности $[2,9,19]$. Особенно остро стоит проблема диагностики развития творческих способностей $[5,15,16,21,23]$. В нашем исследовании предпринята попытка разработать и апробировать диагностический комплекс, который позволил бы всесторонне изучать и оптимизировать процесс музыкально-творческого развития личности. Особенно остро эта проблема стоит в контексте модернизации высшего российского образования, поскольку можно с уверенностью заявить, что в пространстве высшего образования массовое музыкальное образование отсутствует $[4,11]$. Вместе с тем, обратившись к истории отечественного образования, отметим, что в дореволюционной России массовое музыкальное образование было частью образования на любом возрастном этапе.

\section{Методы}

В комплексной диагностической методике музыкально-творческого развития личности студента представлены два направления анализа: первое компетентность в музыкально-творческой деятельности, второе - результативность этой деятельности.

Оценивая готовность студента к музыкально-творческой деятельности, мы анализировали основные ее составляющие. В качестве таковых мы выделили когнитивную, мотивационную, операциональную, рефлексивную, духовно-нравственную готовность.

Особо отметим, что необходимо провести диагностику каждого компонента готовности к творческой деятельности. Для этого важно выявить специфику и определить уровень сформированности каждого компонента. При проведении анализа нами были определены основные критерии изучения и оценки всех компонентов готовности. 


\section{Когнитивная готовность.}

В качестве критериев оценки мы определили следующие моменты: какой стаж музыкальной деятельности студента; каким наличным уровнем музыкального опыта он обладает; какими знаниями музыкальной грамоты, основных средств музыкальной выразительности, знаниями о композиторах и исполнителях, о музыкальных стилях и жанрах, о возможностях творческого самовыражения он владеет.

Когнитивная готовность оценивалась с помощью «Опросника креативности» Д. Джонсона в модификации Е. Туник; авторского теста «Определение уровня музыкальности» (ОУМ); собеседования; опроса; наблюдения; самооценки; контент-анализа высказываний студентов, сочинений - музыкальных впечатлений; анализа продуктов творческой деятельности.

\section{Мотивачионная готовность.}

Критерии оценки: потребность в слушании музыки и занятии музыкальным творчеством; потребность в самоактуализации; отношение к классической музыке; потребность в получении новых музыкальных впечатлений; при выборе композиций для прослушивания возможность эмоциональной избирательности; желание посещать балетные и оперные спектакли, концерты классической музыки; степень мотивации на восприятие сложных музыкальных текстов; увлеченность заданиями теста, продолжительность выполнения задания; разнообразие, оригинальность решений задачи; эмоциональный настрой при выполнении заданий; эмоциональная составляющая продукта творчества (наличие или отсутствие); наличие мотивации к осознанно направленной деятельности (танцевальным движениям, пению, декламации стихов, сочинению стихотворных строк).

Мотивационную готовность студента к музыкально-творческой деятельности мы оценивали с помощью методики «Диагностика психологической структуры мотивационной сферы личности» по В. Э. Мильману; теста на определение уровня музыкальности; теста В. С. Аванесова «Измерение художественно-эстетической потребности»; теста И. М. Пейсахова «Круги»; теста на определение творческих способностей Х. Зиверта; методики «Зелёные пятна» (авторская); опросника креативности Д. Джонсона в модификации Е. Туник; собеседования; опроса; наблюдения; самооценки; психосемиотического анализа сочинений-самонаблюдений, высказываний студента.

\section{Операциональная готовность.}

Критерии оценки: владение студентом навыками пения, способность простучать заданный ритм, качественные характеристики слушания музыки, способность к импровизации; владение разнообразными приемами и техниками творческого самовыражения; способность к комбинированию; умение предложить несколько вариантов решения задачи, предложить творческое 
решение задачи, создать творческий продукт, отличающийся оригинальностью замысла и исполнения; владение навыками интерпретации текста, ассоциативного рисунка; соответствие субъективных образов слушателя объективному содержанию музыки; мастерство исполнения, эстетическая ценность продукта творчества; проявления таланта.

Операциональный компонент готовности к музыкально-творческой деятельности изучался тестом на определение уровня музыкальности (авторский); тестом И. М. Пейсахова «Круги»; методикой «Зелёные пятна» (авторская); тестом X. Зиверта на определение творческих способностей; опросником креативности Д. Джонсона в модификации Е. Туник; а также с помощью наблюдения, самооценки; анализа продуктов и процесса музыкально-творческой деятельности.

\section{Рефлексивная готовность.}

Критерии оценки: уровень развития личностного смысла; способность к философским размышлениям о будущем, о смысле жизни и своем назначении в ней, о взаимоотношениях с окружающими людьми; степень обобщенности ассоциаций; анализ воспоминаний (их наличие или отсутствие); способность к самооценке качественных характеристик самоощущений; уровень конформизма личности при оценке музыкальных произведений; навыки саморегуляции, способность к самодиагностике; умение представлять развернутые, детализированные, поэтичные описания.

Оценка рефлексивного компонента готовности проводилась с использованием теста М. В. Носкова в модификации Н. А. Абыденовой «Уровень духовно-нравственных ориентаций»; методики исследования самоотношения С. Р. Пантилеева - В. В. Столина (МИС); методики Д. Крамбо и Л. Махолика в модификации Д. А. Леонтьева «Изучение смысложизненных ориентаций личности»; методики «Диагностика психологической структуры мотивационной сферы личности» по В. Э. Мильману. Сочинения-музыкальные впечатления, сочинения-самонаблюдения, размышления, высказывания студентов, продукты их творческой деятельности исследовались с помощью метода психосемантического анализа.

Важнейшим компонентом готовности к музыкально-творческой деятельности считаем духовно-нравственную готовность.

Критерии оченки: духовная творческая активность личности; творческий и альтруистический характер жизнедеятельности; ориентация личности на высокие нравственные ценности; высокие духовно-нравственные переживания; интерес к внутреннему миру человека; отношение к другому человеку как самоценности; наличие в сочинениях - музыкальных впечатлениях светлых образов природы, красоты, добра, любви (к людям, к природе, Родине); оптимистичность, философская направленность 
высказываний молодого человека; проявления желания слушать серьезную классическую музыку, наполненную глубоким духовно-нравственным содержанием; эстетическая ценность творческих продуктов, отражающих общечеловеческие ценности.

Духовно-нравственная готовность студента оценивалась методикой «Уровень художественного восприятия» В. А. Веденкиной; диагностической методикой Д. Крамбо и Л. Махолика в модификации Д. А. Леонтьева для изучения смысложизненных ориентаций личности; тестом М. В. Носкова в модификации Н. А. Абыденовой для исследования уровня духовно-нравственных ориентаций; тестом В. С. Аванесова для измерения художественно-эстетической потребности; методикой С. Р. Пантилеева - В. В. Столина для исследования самоотношения (МИС); с помощью психосемантического анализа сочинений студентов, их устных высказываний при обсуждении впечатлений от прослушанной музыки.

\section{Результаты исследования}

Критерии готовности к музыкально-творческой деятельности в совокупности всех ее компонентов послужили основанием для разработки уровней музыкально-творческого развития личности студента в комплексе основных показателей каждого уровня. Были определены 4 уровня музыкальнотворческого развития личности: I (высший) и IV (низший) для студентов вуза. Характеристикам вторичной музыкальной личности соответствовал І уровень (высокий уровень музыкальности), далее следовали II уровень музыкальности - выше среднего, III (средний) уровень музыкальности, IV (низкий) уровень музыкальности [4]. На основе показателей этих четырех уровней проводился анализ музыкально-творческого развития студентов.

Эффективность качественного анализа уровня музыкально-творческого развития личности студента обеспечивает психосемантический анализ их сочинений [5]. Студентам предлагали написать сочинение-размышление, сочинение-самонаблюдение, сочинение - музыкальное впечатление.

Например, в исследовании уровня мотивационной готовности студентам было предложено две темы сочинения (на выбор). Первая тема - «Музыка в моей жизни». Вторая тема звучала так: «Музыка - моя жизнь». Выбор второй темы, по нашему мнению, может свидетельствовать о высшем уровне музыкально-творческого развития личности молодого человека. В контексте нашего исследования это уровень вторичной музыкальной личности.

В сочинении студентам предлагали: представить подробное и детальное описание значение музыки в их жизни; указать предпочтения в музыкальных жанрах, направлениях в музыке, музыкальных стилях; написать, почему занимаются музыкально-творческой деятельностью; указать предпочитаемые 
и доступные для них виды музыкально-творческой деятельности; сообщить о владении музыкальным инструментом или инструментами. Молодые люди также могли рассказать о возможности участия в музыкально-творческом коллективе, руководстве таким коллективом. В сочинении можно было оценить и описать собственные музыкально-творческие способности, личностные качества; степень подготовленности к музыкально-творческой деятельности, успешность в этой деятельности.

Участникам музыкально-творческих коллективов предлагалось подробно рассказать о своих коллективах. Можно было указать цель участия в коллективе; охарактеризовать взаимоотношения участников творческого коллектива; описать эмоциональное состояние, преобладающее в процессе музыкально-творческой деятельности; оценить психологический климат в коллективе; представить ценности, разделяемые членами музыкальнотворческого коллектива.

Студентам в сочинении также предлагали высказать свое мнение о сущности и содержании музыкального искусства, классической музыки, его роли в жизни человека.

Также молодые люди могли написать в сочинении свои представления о будущем, о карьере, семье. Поразмышлять, какую роль в своей жизни они отведут музыке, о будущем музыкального искусства в целом, о необходимости массового музыкального образования.

Эти творческие работы студентов обрабатывались методом контент-анализа. Основные характеристики психологической готовности к музыкальнотворческой деятельности позволили выделить категории контент-анализа. Анализ осуществлялся с целью выявления ориентировочной основы музыкально-творческой деятельности испытуемых, особенностей их мотивации к музыкально-творческой деятельности, определения объема знаний и представлений о музыке в целом и о классической музыке в частности.

В качестве единицы анализа текста выступали предложение, фраза или абзац, которые соответствовали смыслу категории анализа. Трехуровневая шкала отражала степень выраженности категории в анализируемой части текста (единицы счета).

Диагностика мотивационной структуры личности испытуемых была также проведена с использованием более объективного инструментария, в частности методики В. Э. Мильмана.

На основе обобщения данных мотивационной готовности каждого студента определили распределение студентов всей выборки (в процентах) соответственно уровням и рассчитали средний уровневый показатель (СУП) мотивационной готовности всех испытуемых. При расчете СУП использовали методику В. А. Пономаренко, модифицированную в исследованиях В. В. Рыжова [8]. 


\section{Выводы}

В заключение отметим, что представленная комплексная психодиагностическая методика исследования музыкально-творческого развития личности может быть использована на этапе вузовского обучения. Данная методика разработана в рамках авторской концепции музыкально-творческого развития личности в образовательном процессе на основе авторского эстетико-семиотического подхода [4]. Сравнительные результаты формирующего эксперимента, полученные с использованием описанной методики, позволяют оценить количественные и качественные изменения в степени психологической готовности студента вуза к музыкально-творческой деятельности, в целом уровень музыкально-творческого развития личности в процессе высшего образования.

Критерии и методы оценки представленной комплексной психодиагностической методики могут использоваться для оценки эффективности программ психологического сопровождения музыкально-творческого развития личности обучающегося в пространстве высшего образования, тем самым способствуя совершенствованию психолого-педагогической работы по подготовке будущих специалистов с высшим образованием.

\section{Литература}

1. Зинченко Ю. П. Новые возможности высшего психологического образования // Национальный психологический журнал. - 2010. - № 1 (3). C. 86-89.

2. Кирнарская Д. К. Теоретические основы и методы оценки музыкальной одаренности: дисс. ... д-ра психол. наук. - М., 2006. - 373 с.

3. Курышева И. В. Психологические основы музыкально-творческого развития личности в образовательном процессе: автореф. дисс. ... д-ра психол. наук. - Н. Новгород, 2011. - 53 с.

4. Курышева И. В. Психологические основы музыкально-творческого развития личности в образовательном процессе: дисс. ... д-ра психол. наук. - Н. Новгород, 2011. - 453 с.

5. Кыштымова И. М. Психосемиотическая методика диагностики вербальной креативности // Психологический журнал РАН. - 2008. - Т. 29. № 6. - С. 57-67.

6. Пономаренко В. А. Психология духовности профессионала. - М.: Изд-во ИПАН РАН, 2004. - 162 с.

7. Резниченко М. Г. Формирование воспитательного пространства вуза: критерии эффективности // Педагогическое образование и наука. 2009. - № 8. - С. 32-42.

8. Рыжов В. В. Личность: творчество и духовность. - СПб.: Изд-во Санкт- 
Петербургского христианского университета, 2012. - 489 с.

9. Торопова А. В. Феномен музыкального сознания: методология исследования и развития: автореф. дисс. ... д-ра пед. наук. - М., 2009. - 58 с.

10. Торопова A. В. Homo-musicus в зеркале музыкально-психологической и музыкально-педагогической антропологии. - М.: ГРАФ-ПРЕСС, 2008. $288 \mathrm{c}$.

11. Фадеева С. А. Преемственность в музыкально-эстетическом образовании: проблемы, пути решения // Актуальные вопросы подготовки специалиста в контексте современных преобразований: материалы всерос. науч.-практ. семинара. - Орёл, 2006. - С. 208-209.

12. Фигуровская В. М. Элитарное образование: научное содержание и теоретическое обоснование проблемы // Проблемы образования. - Новосибирск: Изд-во НГАЭиУ, 1997. - С. 9-12.

13. Burton J., Horowitz R., Abeles H. Leaning In and Through the Arts. - N. Y.: Columbia University, 2008.

14. Ekvall G., Britz A. Perceptions of the best and worst climates for creativity: preliminary validation evidence for Situational Outlook Questionnaire // Creativity Research Journal. - 2001. - V. 13. - no. 2. - pp. 171-184.

15. Eysenck H. J. Creativity and personality: A theoretical perspective // Psychology Inquiry. - 1993. - V. 4. - pp. 147-178.

16. Guilford J. P. Measurement of creativity. Exploration in creativity. - N. Y.: Mc-Gaw Hill, 1967.

17. James K., Asmus Ch. Personality, cognitive skills and creativity in different life domains // Creativity Research Journal. - 2000. - V. 2. - pp. 149-159.

18. Kurysheva I. V. Fundamental psychophysiology of music therapy of neurological diseases // International Journal of Psychophysiology. - 2008. 69 (3). - P. 302.

19. Seashore C. E. Psychology of Music. - N. Y.: Gemünder, 1990.

20. Sternberg R. J. A three-faset model of Creativity //The nature of creativity. Cambridge, 1998. - pp. 53-92.

21. Torrance E. P. The nature of creativity as manifest in the testing // Sternberg R. The nature of creativity. - Cambridge, 1988. - pp. 43-75.

22. Vorobyeva E., Ermakov P. Training of psychology students in the scientific methods of research // Procedia - Social and Behavioral Sciences. - 2015. V. 191. - pp. 2699-2703.

23. Vorobyeva E., Talalaeva L., Pomazkova N., Sokurenko A., Samoilova N. Age dynamics of verbal creativity at pupils of multidisciplinary institution of additional education // Procedia - Social and Behavioral Sciences. - 2014. v. 146. - pp. 483-486. 